\title{
Phytochemical Screening, In vitro and In vivo Antioxidant Activities of Aqueous Extract of Anacardium occidentale Linn. and its Effects on Endogenous Antioxidant Enzymes in Hypercholesterolemic Induced Rabbits
}

\author{
${ }^{1}$ F. Fazali, ${ }^{1}$ A. Zulkhairi, ${ }^{2}$ M.E. Nurhaizan, ${ }^{1}$ N.H. Kamal, ${ }^{3}$ M.S. Zamree and ${ }^{3}$ M.A. Shahidan \\ ${ }^{1}$ Department of Human Anatomy, ${ }^{2}$ Department of Nutrition and Dietetic, \\ Faculty of Medicine and Health Sciences, University Putra Malaysia, Selangor, Malaysia \\ ${ }^{3}$ Herbal Technology Centre, Forest Research Institute of Malaysia, Selangor, Malaysia
}

\begin{abstract}
Oxidative stress has been shown to play important role in the development of various diseases. In this study, researchers investigated the existence of phytochemical constituents of Anacardium occidentale Linn. (AO) leaf and evaluate its in vitro and in vivo antioxidant activities in aqueous extract form. Phytochemical screening of AO was performed according to the standard method while in vitro antioxidant activities were performed via DDPH free radical scavenging and Ferric reducing antioxidant power assay. In vivo antioxidant activities were evaluated in hypercholesterolemic induced adult male New Zealand white rabbits. Phenolic, flavonoids, steroids and triterpenes were found in the leaf of AO. The freeze dried aqueous extract showed no significant different compared to BHT in in vitro antioxidant analysis when assessed using the FRAP assay. Supplementation of aqueous extract of AO $(100,200 \mathrm{mg} / \mathrm{kg} /$ day $)$ to the hypercholesterolemic induced rabbits caused a significant decreased $(p<0.05)$ of malondialdehyde and significant increased $(p<0.05)$ of superoxide dismutase and catalase levels at the end of the study period compared to the groups received high cholesterol diet alone. Aqueous extract of $\mathrm{AO}$ possess the ability to act as an antioxidant in vitro and in vivo and also was able to increase the level of superoxide dismutase and catalase in experimental hypercholesterolemia. The presence of flavonoids in the extract could be attributed to the antioxidative effect of the plant.
\end{abstract}

Key words: Anacardium occidentale, antioxidant enzymes, flavonoids, DPPH, FRAP, Malaysia

\section{INTRODUCTION}

Hypercholesterolemia diet was reported to bring remarkable modifications in the antioxidant defense system (Fki et al., 2005) thus causing oxidative stress, the disturbances of the delicate balance between oxidants and antioxidants (Mazor et al., 1997). The consumption of a cholesterol enriched diet also has been documented to increases the degree of lipid peroxidation (Hakimoglu et al., 2007). However under normal conditions, the production of reactive oxygen species will be quickly eliminated by antioxidant defense mechanisms to prevent such event (Hsu et al., 2001). The antioxidant enzymes such Catalase (CAT), Glutathione Peroxidase (GPx) and the Superoxide Dismutase (SOD) was proposed to act as a 1st line of defense system to intercept the free radicals interaction (Rashtchizadeh et al., 2008).

Anacardium occidentale Linn. (AO), one of the commonly consumed traditional vegetables among Malays and indigenous community in Malaysia is a tree native to Brazil that is presently cultivated in many regions of the world including Malaysia. As reported in phytochemical tests, cashew leaves contain various flavonoids, mainly quercetin glycosides. Recently, two studies have reported the antioxidant activities of the leaves of $\mathrm{AO}$ (Roach et al., 2003; Abas et al., 2006). This present research examines the possibility of aqueous extract of $\mathrm{AO}$ to act as antioxidant agent by determining its antioxidative properties in vitro and in vivo.

\section{MATERIALS AND METHODS}

Collection and identification of plant materials: Fresh leaves of Anacardium occidentale Linn. were collected from Kelantan, Malaysia. The leaves were identified and authenticated by a plant taxonomist in Institute of Bioscience, Universiti Putra Malaysia (Voucher Specimen No: SK233)

Extract preparation: The methanol and chloroform extract of Anacardium occidentale Linn. were prepared by soaking $100 \mathrm{~g}$ of powdered leaves in $1000 \mathrm{~mL}$ methanol

Corresponding Author: A. Zulkhairi, Department of Human Anatomy, Faculty of Medicine and Health Sciences, University Putra Malaysia, Selangor, Malaysia 
and $1000 \mathrm{~mL}$ chloroform, respectively at room temperature for $48 \mathrm{~h}$. The aqueous extract was prepared by soaking $100 \mathrm{~g}$ of the powdered leaves in $1000 \mathrm{~mL}$ distilled water and incubated in shaking water bath at temperature of $60^{\circ} \mathrm{C}$ and incubation time of $6 \mathrm{~h}$. Following extraction, the all extracts were filtered and the supernatant were concentrated using a rotary evaporator with the water bath set at $40^{\circ} \mathrm{C}$ for methanol and chloroform extract while the aqueous extract was subjected to freeze dried. The methanol and chloroform extract were kept in a desiccator while the freeze dried extract was kept in dark air tight container at $-20^{\circ} \mathrm{C}$ until further used. The freeze dried powder was mixed with water ( $100 \mathrm{mg}$ in $1 \mathrm{~mL}$ water) to dissolve it before administrated to the rabbits.

Phytochemical analysis: The presence of possible phytochemicals constituents in the extract were evaluated qualitatively (alkaloids, saponins, steroid and triterpenoids, tannins, flavonoid).

Test for alkaloids: About $1 \mathrm{~mL}$ of chloroform extract of $\mathrm{AO}$ added with $1 \%$ of hydrochloric acid on steam bath and then filterated. About $1 \mathrm{~mL}$ filtrate then was added with 6 drops of Mayer's reagent. Appearance of cream white precipitate indicated the presence of alkaloids (Harborne, 1996).

Test for saponins: About $1 \mathrm{~mL}$ of methanol extract of $\mathrm{AO}$ added with $9 \mathrm{~mL}$ of distilled water was shaken vigorously and appearance of stable froth for at least $15 \mathrm{~min}$ indicated the presence of saponins (Harborne, 1996).

Test for steroids and triterpenoids: About $2 \mathrm{~mL}$ of chloroform extract of $\mathrm{AO}$ added was with $1 \mathrm{~mL}$ of chloroform and a few drops of acetic anhydride and a few drops of concentrated sulfuric acid. Appearance of blue or green color indicated the presence of steroids and appearance of red, brown color indicates the presence of triterpenoids (Harborne, 1996).

Test for tannins: The methanolic extract of $\mathrm{AO}$ was mixed with a few drops of $1 \%$ ferric chloride solution. Formation of blue-black colour indicates the presence of hydrolysable tannins while the formation of blue-green precipitate indicates the presence of condensed tannins (Trease and Evans, 2002).

Test for flavonoids: A portion of the methanolic extract of AO was heated with $10 \mathrm{~mL}$ of ethyl acetate over a steam bath for $3 \mathrm{~min}$. The mixture was filtered and $4 \mathrm{~mL}$ of the filtrate was shaken with $1 \mathrm{~mL}$ of dilute ammonia solution. A yellow colouration indicates the presence of flavonoids (Sofowora, 1982).
Test for phenolic content: About $200 \mu \mathrm{L}\left(0.2 \mathrm{mg} \mathrm{mL}^{-1}\right)$ aqueous extract solution was mixed with $0.75 \mathrm{~mL} 10$-fold diluted Folin-ciocalteu reagent. Following $5 \mathrm{~min}$ of incubation, $0.75 \mathrm{~mL}$ of $6 \% \mathrm{Na}_{2} \mathrm{CO}_{3}$ solution was added and the mixture was allowed to stand for $90 \mathrm{~min}$ at room temperature. Brown colour indicates the presence of phenolic compounds (Velioglu et al., 1998).

\section{In vitro antioxidant analysis}

DPPH free radical scavenging: The potential antioxidant activity of the aqueous extracts of $\mathrm{AO}$ was assessed on the basis of scavenging activity of the stable 1, 1-Diphenyl-2-Picrylhydrazyl (DPPH) free radical according to the previous described procedure (Yen and Hsieh, 1998). For the control, $1 \mathrm{~mL}$ of $0.45 \mathrm{mM} \mathrm{DPPH}$ is added into $0.5 \mathrm{~mL}$ absolute ethanol. For the sample, $1 \mathrm{~mL}$ of $0.45 \mathrm{mM} \mathrm{DPPH}$ were added with $0.5 \mathrm{~mL}$ extract $(5 \mathrm{~mL})$. The step is repeated by replacing extract with BHT $\left(5 \mathrm{mg} \mathrm{mL}{ }^{-1}\right.$ ). All samples were incubated for $30 \mathrm{~min}$ and following incubation, absorbance is read at $517 \mathrm{~nm}$. The percentage of inhibition of the sample against DPPH radicals was calculated from the following equation:

[Absorbance of control -

$$
\text { Inhibition }(\%)=\frac{\text { Absorbance of test sample] }}{\text { Absorbance of control }} \times 100
$$

Ferric Reducing Antioxidant Power (FRAP): The ferric reducing ability of $A$. occidentale Linn. aqueous extract was evaluated following the method described by Benzie and Strain (1996). About $100 \mu \mathrm{L}$ of sample (studied extracts) were mixed with $300 \mathrm{~mL}$ distilled water and $3 \mathrm{~mL}$ of FRAP reagent $(2.5 \mathrm{~mL}$ of $10 \mathrm{mM}$ of $2,4,6$-Tris (2-Pyridyl)-1, 3, 5-Triazine (TPTZ) solution in $40 \mathrm{mM} \mathrm{HCl}$ added with $2.5 \mathrm{~mL}$ of $20 \mathrm{mM} \mathrm{FeCl}_{3}$ added with $25 \mathrm{~mL}$ of $0.3 \mathrm{M}$ acetate buffer, pH 3.6) was mixed. Absorbance was read at $593 \mathrm{~nm}$. The final results were expressed as the concentration of antioxidants having ferric reducing ability equivalent to that of $1 \mathrm{mM} \mathrm{FeSO}_{4}$, particularly expressed in milimolar per liter.

Animals and experimental protocol: Total 35 healthy adult male New Zealand White rabbits weighting between 1.8 and $2.0 \mathrm{~kg}$ were used in the experiments (East Asia Rabbits Corporation Sdn Bhd). The animals were randomly housed in an individual cage with free access to food and water in standard conditions of lighting, temperature and humidity for 2 weeks for acclimatization. Following acclimatization, the rabbits were divided into five groups $(n=7)$ and were fed accordingly; Normal Control group $(\mathrm{NC})$ rabbits was fed the standard diet, atherogenic rabbits group (PC) was fed the standard diet 
enriched with $0.5 \%$ cholesterol, Simvastatin group (SC) rabbits was fed the standard diet enriched with $0.5 \%$ cholesterol with $10 \mathrm{mg} / \mathrm{kg} /$ day simvastatin, treatment groups (AOE100, AOE200) were fed the standard diet enriched with $0.5 \%$ cholesterol with different doses of water extract of $\mathrm{AO}(100,200 \mathrm{mg} / \mathrm{kg} /$ day $)$. Animals were fasted for $12 \mathrm{~h}$ before venous blood samples were collected at week 0,4 and 8 th. At the end of the experimental period, the animals were then sacrificed via exsanguinations and aorta was collected for histological study. The animals handling procedure in this study was approved in strict accordance with the Animal Care and Use Committee of Faculty of Medicine and Health Sciences, University Putra Malaysia (UPM) Serdang, Selangor.

Endogenous antioxidant enzymes analysis: There are four antioxidant enzymes evaluated; Superoxide Dismutase (SOD), Glutathione Peroxidase (GPx), Total Antioxidant Status (TAS) and Catalase (CAT). Quantitative determination of SOD, GPx and TAS were done using commercial kits from Randox (UK) while Catalase from Cayman's (Canada).

Measurement of lipid peroxidation index malondialdehyde: The lipid peroxidation index is measured using Thiobarbituric Acid (TBA) test on Malondialdehyde (MDA) according to method described by Ledwozyw et al. (1986) and determination of protein concentration in the sample was based on the method of Lowry protein assay (Lowry et al., 1951).

Statistical analysis: The data obtained were analyzed using the Statistical Package for Social Science (SPSS) program Version 15. After confirming the normality of data and the homogeneity of variance of data, the significance of the differences between means of the tests and control studies was established by one-way Analysis of Variance (ANOVA) coupled with post hoc Tukey HSD for multiple group comparison and $\mathrm{p}<0.05$ was used to denote of statistically significant. Results are expressed as a mean \pm SD.

\section{RESULTS AND DISCUSSION}

Phytochemical analysis: Phytochemical study of $\mathrm{AO}$ revealed the presence of phenolic, flavonoids, steroids and triterpenes while other constituents such as alkaloids, saponins and tannins were not detected (Table 1). Several studies have reported a significant correlation between antioxidant activities present in some tropical vegetables with their total phenolic content (Maisutthisakul et al.,

2008). Study by Kogel and Zech (1985) reported the presence of several phenolic acids in the leaves of $\mathrm{AO}$, mainly gallic acid, protocatechuic acid, p-hydroxybenzoic acid, cinnamic acid, p-coumaric acid and ferulic acid. Flavonoids and tannins are phenolic compounds, a major group of compounds that act as primary antioxidants or free radical scavengers. They also posses redox properties therefore, allowing them to act as reducing agents, hydrogen donators and singlet oxygen quenchers (Pietta et al., 1998) and to some extent, metal chelator (Kumarasamy et al., 2004). Other researchers, Luzzi and Maiani (1999) suggested that excess flavonoids can be stored in body tissues and mobilized in response to physiological requirements.

In vitro antioxidant analysis: As a complex matrix of interacting factors therefore, it has become more accepted to evaluate the antioxidant capacity of foods to give an index of healthiness (Van Boekel and Jongen, 1997). One of widely used techniques to assess the antioxidant capacity of plants is DPPH free radical scavenging activity. In this technique, the radical scavenging abilities and the reducing potentials of the antioxidant constituent of plant extract towards the stable radical DPPH was evaluated (Sanchez-Moreno, 2002). Previous study indicated that methanol extract of $\mathrm{AO}$ with $\mathrm{IC}_{50}$ value of 72 $\mu \mathrm{g}$ dried extract $\mathrm{mL}^{-1}$ were able to inhibit the formation of $\mathrm{DPPH}$ radicals with a percentage inhibition of $90.7+0.2 \%$ at the concentration of $400 \mathrm{~g} \mathrm{~mL}^{-1}$ (Razali et al., 2008). The study showed that the percentage of inhibition of aqueous extract of $A$. occidentale L. against the DPPH radicals is $78.325+0.241 \%$ (Table 2 ). The reducing ability of $A$. occidentale L. aqueous extracts against the ferric ion which acts as the oxidants is shown in Table 2.

Table 1: Phyto-chemical analysis

\begin{tabular}{ll}
\hline Constituents & Results \\
\hline Alkaloids & ND \\
Saponins & ND \\
Flavonoids & +++ \\
Tannins & $\mathrm{ND}$ \\
Triterpenes & + \\
Steroids & ++ \\
Phenolic & +++ \\
\hline ND = Not Detected; $+=$ Weak colour; $++=$ Mild colour; $+++=$ Strong
\end{tabular}

Table 2: In vitro antioxidant evaluation

\begin{tabular}{lr}
\hline Extracts & Values \\
\hline DPPH free radical scavenging & \\
Freeze dried aqueous extract (\%) & $78.325 \pm 0.241^{\mathrm{a}}$ \\
BHT (\%) & $91.893 \pm 1.792^{\mathrm{b}}$ \\
Ferric reducing antioxidant power & \\
Freeze dried aqueous extract $\left(\mathrm{mmol} \mathrm{L}^{-1}\right)$ & $1.811 \pm 0.089^{\mathrm{a}}$ \\
BHT (mmol L ${ }^{-1}$ ) & $1.977 \pm 0.005^{\mathrm{a}}$ \\
\hline Each value represents the mean $\pm \mathrm{SD}$. The same alphabet are not significantly & \\
different $(\mathrm{p}<0.05$ ) within groups &
\end{tabular}


The assay shows that Butylated Hydroxytoluene (BHT) which acts as standard had the highest antioxidant activity of $1.977 \pm 0.005 \mathrm{mmol} \mathrm{L}^{-1}$. Freeze dried extract of AO demonstrated FRAP value of $1.811 \pm 0.089 \mathrm{mmol} \mathrm{L}^{-1}$ with no significant different denoted between BHT and the extract. Hence, the reductive ability of the extracts suggests that the extracts were able to donate electron therefore suggesting that they may be able to donate electrons to free radicals in actual biological systems. Previous study demonstrated that in the leaves itself, pure gallic acid and ferullic acid which were detected previously (Kogel and Zech, 1985) and were found to be able to reduce ferric ions when assessed by FRAP assay (Soobrattee et al., 2005) thus suggesting that the results obtained may have partly been contributed by these phenolics.

In vivo antioxidant analysis: It is previously reported that the GPx activity is decreased while CAT activity is increased (Prasad and Kalra, 1993: Mahfouz et al., 1997) in hypercholesterolemic induced rabbits compared to control group at the end of the study period. However, Mahfouz et al. (1997) does not observe any significant change in the SOD activity which contradicted with that of Prasad and Kalra (1993). The present study revealed no significant changes in GPx and SOD activity but significant increased of catalase activity of blood from cholesterol-fed rabbits (Table 3), contradicted to what has been reported. The differences could be due to the duration of the study period and the amount of cholesterol loaded.
Supplementation of Anacardium occidenlate Linn. (AO) in hypercholesterolemia event of all doses, however did not improved the level of GPx activity in cholesterol-fed rabbits at the end of the study period compared to PC group. However, SOD and catalase levels at the end of study period were significantly higher $(p<0.05)$ compared to PC group. The decreased in GPx level is possibly due to its increased utilization in combating excessive erythrocytes oxidative stress in hypercholesterolemic rabbits. The decreased in GPx would lower the erythrocyte capacity to deal with $\mathrm{H}_{2} \mathrm{O}_{2}$ and possibly lead to an increased in catalase activity as an adaptation process (Mahfouz et al., 1997). Flavonoids compounds have the ability to decrease oxidative stress by promoting the cellular consumption of glutathione by inactivating selenium-dependent glutathione peroxidase (Cai et al., 1997) and increase the expression of antioxidant enzymes such as superoxide dismutase, catalase and glutathione peroxidase (Rohrdanz et al., 2002).

Lipid peroxidation index malondialdehyde analysis: Malondialdehyde (MDA), one of end product of lipid peroxidation has become the principal and the most studied product of polyunsaturated fatty acid peroxidation (Del Rio et al., 2005). The MDA level in plasma in PC group at the end of the study period was significantly higher than other groups (Table 4). The increased of MDA in cholesterol-fed rabbits agrees with previous reports (Mahfouz et al., 1997). In AO treatment groups, MDA level in plasma significantly low $(\mathrm{p}<0.05)$

Table 3: Comparison of in vivo antioxidant enzymes levels at week 0,4 and 8 th of experimental period

\begin{tabular}{|c|c|c|c|c|c|}
\hline \multirow[b]{2}{*}{ Bio-chemical factors } & \multicolumn{5}{|l|}{ Groups } \\
\hline & $\mathrm{NC}$ & $\mathrm{PC}$ & $\mathrm{SC}$ & AOE 100 & AOE 200 \\
\hline \multicolumn{6}{|l|}{$\operatorname{SOD}\left(\mathrm{U} \mathrm{L}^{-1}\right)$} \\
\hline $\mathrm{w}=0$ & $2.65 \pm 0.0300^{2,1}$ & $2.66 \pm 0.0300^{\mathrm{a}, 1}$ & $2.61 \pm 0.0400^{\mathrm{a}} 1$ & $6.74 \pm 0.300^{b, 1}$ & $6.70 \pm 0.260^{b, 1}$ \\
\hline $\mathrm{w}=4$ & $2.65 \pm 0.0100^{c, 1}$ & $2.69 \pm 0.0200^{c, 1}$ & $2.69 \pm 0.0400^{c, 1}$ & $1.32 \pm 0.060^{\mathrm{d} 2}$ & $1.33 \pm 0.050^{\mathrm{d} 2}$ \\
\hline $\mathrm{w}=8$ & $4.48 \pm 0.5400^{e, 2}$ & $5.02 \pm 0.1400^{e, 2}$ & $3.45 \pm 0.0800^{f, 2}$ & $9.73 \pm 0.240,3$ & $9.93 \pm 0.300,3$ \\
\hline \multicolumn{6}{|l|}{ GPx $\left(U_{L^{-1}}\right)$} \\
\hline $\mathrm{w}_{1}=0$ & $657.68 \pm 52.880^{2,1}$ & $409.47 \pm 46.760^{b, 1}$ & $432.88 \pm 41.140^{b, 1}$ & $670.01 \pm 14.85^{a}, c, 1$ & $698.10 \pm 22.380^{\mathrm{a}}$ \\
\hline$w=4$ & $634.21 \pm 16.390^{\mathrm{d}, 1}$ & $824.02 \pm 103.17^{\mathrm{d}, \mathrm{e}, 2}$ & $825.37 \pm 4.0000^{e, f, g, 2}$ & $732.90 \pm 33.47^{\mathrm{d}, e, f, 2}$ & $895.77 \pm 37.410^{g}$ \\
\hline $\mathrm{w}=8$ & $699.57 \pm 102.40^{\mathrm{h} .1}$ & $827.96 \pm 79.370^{\mathrm{h}, 2}$ & $922.00 \pm 38.720^{i 3}$ & $404.99 \pm 13.36^{3}$ & $477.37 \pm 52.750^{\mathrm{j}, 3}$ \\
\hline \multicolumn{6}{|l|}{ CAT $(\mathrm{nmol} / \mathrm{min} / \mathrm{mL})$} \\
\hline $\mathrm{w}=0$ & $0.026 \pm 0.004^{2,1}$ & $0.025 \pm 0.004^{4,1}$ & $0.027 \pm 0.004^{\mathrm{a}, 1}$ & $0.028 \pm 0.004^{4,1}$ & $0.026 \pm 0.004^{\mathrm{a}, 1}$ \\
\hline $\mathrm{w}=4$ & $0.030 \pm 0.002^{b, 1}$ & $0.037 \pm 0.004^{c, 2}$ & $0.032 \pm 0.002^{b, c, 1}$ & $0.030 \pm 0.004^{b, 1}$ & $0.030 \pm 0.003^{b, c, 1}$ \\
\hline$\underline{w}=8$ & $0.026 \pm 0.003^{\mathrm{d}, 1}$ & $0.040 \pm 0.003^{\mathrm{e}, 2}$ & $0.027 \pm 0.004^{\mathrm{d} .1}$ & $0.060 \pm 0.004^{\mathrm{f}, 2}$ & $0.071 \pm 0.004^{\mathrm{g}, 2}$ \\
\hline
\end{tabular}

Table 4: Comparison of lipid peroxidation index: TBARs levels at week 0,4 and 8 th of experimental period

\begin{tabular}{|c|c|c|c|c|c|}
\hline \multirow[b]{2}{*}{ Bio-chemical factors } & \multicolumn{5}{|l|}{ Groups } \\
\hline & $\mathrm{NC}$ & $\mathrm{PC}$ & $\mathrm{SC}$ & AOE 100 & $\mathrm{AOE} 200$ \\
\hline MDA (nmol mg ${ }^{-1}$ protein) & & & & & \\
\hline $\begin{array}{l}w=0 \\
w=4\end{array}$ & $\begin{array}{l}0.776 \pm 0.078^{\mathrm{a}, 1} \\
0.834+0.055^{\mathrm{b}, 1}\end{array}$ & $0.722 \pm 0.040^{2,1}$ & $0.786 \pm 0.065^{\mathrm{a}, 1}$ & $0.728 \pm 0.021^{\mathrm{a}, 1}$ & $\begin{array}{l}0.792 \pm 0.037^{\mathrm{a}, 1} \\
1.069 \pm 0.446^{\mathrm{c}, 1}\end{array}$ \\
\hline $\begin{array}{l}w=4 \\
w=8\end{array}$ & $0.745 \pm 0.041^{\mathrm{d}, 1}$ & $1.348 \pm 0.323^{\mathrm{e}, 2}$ & $0.919 \pm 0.072^{\mathrm{d}, e, 1,2}$ & $1.057 \pm 0.341^{\mathrm{d}, e, 1,2}$ & $0.727 \pm 0.073^{\mathrm{d}}$ \\
\hline
\end{tabular}

Each value represents the mean $\pm \mathrm{SD}$; the same alphabet are not significantly different $(\mathrm{p}<0.05)$ between groups at specific time interval; the same number are not significant different $(\mathrm{p}<0.05)$ within groups 
compared to PC group at the end of the study period. It was previously demonstrated that the addition of free radical scavengers to a cholesterol supplemented diet significantly decreased the plasma lipid peroxidation products (Matz et al., 1994). Flavonoids can potentially prevent free radical related injury such as lipid peroxidation as they exhibit powerful antioxidant activities in vitro. They are able to scavenge a wide range of reactive oxygen, nitrogen and chlorine species (Santos and Mira, 2004; Sadeghipour et al., 2005) as well as being able to inhibit the production of such reactive species (Selloum et al., 2001).

\section{CONCLUSION}

The results showed the ability of aqueous extract of $\mathrm{AO}$ to act as antioxidant in vitro demonstrated by the high FRAP value and the high percentage of inhibition of $\mathrm{DPPH}$ free radical and in vivo demonstrated by the low MDA level. The study also found that the extract was able to increase the level of certain antioxidant enzymes activity such SOD and catalase thereby suggesting the potential beneficial usage of the plant to treat various diseases related to the oxidative stress. The presence of flavonoids compounds could be attributed for such effects.

\section{ACKNOWLEDGEMENTS}

This study was supported by a grant (Project No: 02-01-04-SF0042) from the Ministry of Science and Technology (MOSTI), Malaysia. Thanks to the laboratory facilities and expertise provided by Anatomy Research Laboratory, Faculty of Medicine and Health Sciences, University Putra Malaysia, Selangor, Malaysia and Herbal Technology Center, Forest Research Institute of Malaysia, Selangor, Malaysia.

\section{REFERENCES}

Abas, F., N.H. Lajis, D.A. Israf, S. Khozirah and Y. UmiKalsom, 2006. Antioxidant and nitric oxide inhibition activities of selected Malay traditional vegetables. Food Chem., 95: 566-573.

Benzie, I.F.F. and J.J. Strain, 1996. The Ferric Reducing Ability of plasma (FRAP) as a measure of antioxidant power: The FRAP assay. Anal. Biochem., 239: 70-76.

Cai, Q., R.O. Rahan and R. Zang, 1997. Dietary flavonoids, quercetin, luteolin and genistein, reduce DNA damage and lipid peroxidation and quench free radicals. Cancer Lett., 119: 99-107.
Del Rio, D., A.J. Stewart and N. Pellegrini, 2005. A review of recent studies on malondialdehyde as toxic molecule and biological marker of oxidative stress. Nutr. Metab. Cardiovas. Dis., 15: 316-328.

Fki, I., M. Bouaziz, Z. Sahnoun and S. Sayadi, 2005. Hypocholesterolemic effects of phenolic-rich extracts of Chemlali olive cultivar in rats fed a cholesterolrich diet. Bioorganic Med. Chem., 13: 5362-5370.

Hakimoglu, F., G. Kizil, Z. Kanay, M. Kizil andH. Isi, 2007. The effect of ethanol extract of Hypericum lysimachioides on lipid profile in hypercholesterolemic rabbits and its in vitro antioxidant activity. Atherosclerosis, 192: 113-122.

Harborne, J.B., 1996. Phytochemical Methods. Chapman and Hall, London, pp: 52-105.

Hsu, H.C., Y.T. Lee and M.F. Chen, 2001. Effects of fish oil and vitamin $\mathrm{E}$ on the antioxidant defense system in diet-induced hypercholesterolemic rabbits. Prostaglandins Other Lipid Mediat., 66: 99-108.

Kogel, I. and W. Zech, 1985. The phenolic acid content of cashew leaves (Anacardium occidentale L.) and of the associated humus layer, Senegal. Geoderma, 35: 119-125.

Kumarasamy, Y., M. Byres, P.J. Cox, A. Delazar and M. Jaspars et al., 2004. Isolation, structure elucidation and biological activity of flavone 6-cglycosides from Alliaria petiolata. Chem. Nat. Compd., 40: 122-128.

Ledwozyw, A., J. Michalak, A. Stepien and A. Kadziolka, 1986. The relationship between plasma triglycerides, cholesterol, total lipid and lipid peroxidation product during human arterosclerosis. Clin. Chem. Acta, 155: $275-283$.

Lowry, O.H., N.J. Rosebrough, A.L. Farr and R.J. Randall, 1951. Protein measurement with the folin phenol reagent. J. Biol. Chem., 193: 265-275.

Luzzi, A.F. and G. Maiani, 1999. Biomarkers of Flavonoid Intake in Human. In: Natural Antioxidants and Anticarcinogens in Nutrition, Health and Disease, Kumpulainen, J.T. and J.T. Salonen (Eds.). MPG Books Ltd., Helsinki, pp: 124-136.

Mahfouz, M.M., H. Kawano and A.K. Kummerow, 1997. Effect of cholesterol-rich diets with and without added vitamins $\mathrm{E}$ and $\mathrm{C}$ on the severity of atherosclerosis in rabbits. Am. J. Clin. Nutr., 66: $1240-1249$.

Maisutthisakul, P., S. Pasuk and P. Rithiruangdej, 2008. Relationship between antioxidant properties and chemical composition of some Thai plants. J. Food Comp. Anal., 21: 229-240. 
Matz, J., T.L.G. Andersson, G.A.A. Ferns and E.E. Anggard, 1994. Dietary vitamin $\mathrm{E}$ increases the resistance to lipoprotein oxidation and attenuates endothelial dysfunction in the cholesterol-fed rabbit. Atherosclerosis, 110: 241-249.

Mazor, D., G. Brill, Z. Shorer, S. Moses and N. Meyerstein, 1997. Oxidative damage in red cells of vitamin $\mathrm{E}$ deficient patients. Clin. Chim. Acta, 265: 131-137.

Pietta, P., P. Simonetti and P. Mauri, 1998. Antioxidant acticity of selected medicinal plants. J. Agric. Food Chem., 46: 4487-4490.

Prasad, K. and J. Kalra, 1993. Oxygen free radicals and hypercholesterolemic atherosclerosis. Am. Heart J., 125: 958-971.

Rashtchizadeh, N., S. Ettehad, R.A. Di Silvestro and R. Mahdavi, 2008. Antiatherogenic effects of zinc are associated with copper in iron-overloaded hypercholesterolemic rabbits. Nutr. Res., 28: 98-105.

Razali, N., R. Razab, S.M. Junit and A.A. Aziz, 2008. Radical scavenging and reducing properties of extracts of cashew shoots (Anacardium occidentale). Food Chem., 111: 38-44.

Roach, P.D., M.N. Salleh, I. Runnie, S. Mohamed and M.Y. Abeywardena, 2003. Inhibition of low density lipoprotein oxidation and upregulation of the low density lipoprotein receptor of human liver HEPG2 cells by tropical plant extracts. Clin. Exp. Pharmacol. Physiol., 30: 5-6.

Rohrdanz, E., S. Ohler, Q.H. Tran-Thi and R. Kahl, 2002. The phytoestrogen daidzein affects the antioxidant enzyme system of rat hepatoma H4IIE cells. J. Nutr., 132: 370-375.

Sadeghipour, M., R. Terreux and J. Phipps, 2005. Flavonoids and tyrosine nitration: Structure-activity relationship correlation with enthalpy of formation. Toxicol. In vitro, 19: 155-165.
Sanchez-Moreno, C., 2002. Review: Methods used to evaluate the free radical scavenging activity in foods and biological systems. Food Sci. Technol. Int, 8: $121-137$.

Santos, M.R. and L. Mira, 2004. Protection by flavonoids against the peroxynitrite-mediated oxidation of dihydrorhodamine. Free Radic. Res., 38: 1011-1018.

Selloum, L., S. Reichl, M. Muller, L. Sebihi and J. Arnhold, 2001. Effects of flavonols on the generation of superoxide anion radicals by xanthine oxidase and stimulated neutrophils. Arch. Biochem. Biophys., 395: 49-56.

Sofowora, A., 1982. Medicinal Plants and Traditional Medicine in Africa. 1st Edn., John Wiley and Sons, Chichester, New York, ISBN-10: 0471103675,pp: 256.

Soobrattee, M.A., V.S. Neergheen, A. Luximon-Ramma, O.I. Aruoma and T. Bahorun, 2005. Phenolics as potential antioxidant therapeutic agents: Mechanism and actions. Mutat. Res., 579: 200-213.

Trease, G.E. and W.C. Evans, 2002. Pharmacognosy. 15th Edn., WB Saunders, London, ISBN: 8131200876 , pp: 406.

Van Boekel, M.A.J.S. and W.M. Jongen, 1997. Product quality and food processing: How to quantify the healthiness of a product. Cancer Lett., 114: 65-69.

Velioglu, Y.S., G. Mazza, L. Gao and B.D. Oomah, 1998. Antioxidant activity and total phenolics in selected fruits, vegetables and grain products. J. Agric. Food Chem., 46: 4113-4117.

Yen, G.C. and C.L. Hsieh, 1998. Antioxidant activity of extracts from Du-zhong (Eucommia ulmoides) toward various lipid peroxidation models in vitro. J. Agric. Food Chem., 46: 3952-3957. 